\title{
CONTRIBUIÇÃO DIDÁTICA E CIRÚRGICA DA EXPOSIÇÃO TRIDIMENSIONAL DOS RAMOS DO NERVO FACIAL
}

Isabelle Ribas Lima e SILVA, Wanderley da Silva FELIX JÚNIOR, Armin WEBER, Djanira Aparecida da Luz VERONEZ

A investigação visual e manual das estruturas anatômicas da cabeça e pescoço são métodos utilizados nos atos cirúrgicos, bem como o treinamento da habilidade cirúrgica usando cadáveres representa o ambiente ideal, entretanto sua disponibilidade reduzida e problemas éticos limitaram o seu amplo uso. Neste contexto os objetivos desse trabalho foram desenvolver material alternativo viável para exposição dos ramos endocranianos, endotemporais e exocranianos do nervo facial através da construção de maquetes tridimensionais, fornecer subsídios para comparação com as peças anatômicas cadavéricas e oferecer complementação e maior elucidação durante o estudo prático didático e cirúrgico. Para isso desenvolvemos duas maquetes a partir de moldes de crânios humanos macerados como substrato anatômico para a distribuição dos ramos do nervo facial. O preparo de maquetes foi um processo artesanal que exigiu paciência, dedicação e conhecimento para expor as estruturas anatômicas pretendidas com fidelidade, qualidade e apresentação esteticamente satisfatória. Com 0 uso das maquetes nas aulas práticas percebemos ser uma excelente ferramenta para complementação do estudo prático. A produção das maquetes como modelo anatômico didático cirúrgico permitiu concluir que é possível gerar informações morfológicas tridimensionais para maior elucidação no estudo anatômico da inervação da face pelos ramos do nervo facial.

Palavras-chave: Anatomia; Nervo facial; Cirurgia. 